\title{
Laws of Gas Diffusion in Coal Particles: A Study Based on Experiment and Numerical Simulation
}

\author{
Yongjiang Hao $₫$, Xiaofeng Ji $\odot$, and Jiewen Pang $₫$ \\ School of Safety and Emergency Management Engineering, Taiyuan University of Science and Technology, Taiyuan 030024, China \\ Correspondence should be addressed to Yongiiang Hao; haoyongiiang@163.com
}

Received 26 June 2021; Accepted 28 July 2021; Published 19 August 2021

Academic Editor: Feng Du

Copyright ( 2021 Yongjiang Hao et al. This is an open access article distributed under the Creative Commons Attribution License, which permits unrestricted use, distribution, and reproduction in any medium, provided the original work is properly cited.

\begin{abstract}
In order to research on the law of methane released through the pore in coal particles, the methane desorption experiments were conducted, respectively, on four types of particle size of coal samples under three different initial adsorption pressures. The cumulative methane desorption quantity (CMDQ) with time increasing was obtained to show that the reciprocal of CMDQ was in linear relation with the reciprocal of the square root of time, and the correlation coefficients were all above 0.99, on basis of which an empirical formula of CMDQ was established. Then, according to Fick diffusion law and Darcy percolation law, the mathematical models of methane emission from the spherical coal particles were created, respectively, and the corresponding calculating software was programmed by the finite difference method to obtain the simulated CMDQ of each sample under different conditions. The methane emission rate functions (MERF) of the simulation and the experiment were also calculated, respectively. Comparative analysis between the numerically simulated outcomes and the assay results reveals that the simulation outcomes as per Darcy's law match the experimental data better, while the simulated results by Fick's law deviate greatly, which indicates that the methane flowing through coal particles is more in accordance with Darcy's law.
\end{abstract}

\section{Introduction}

In China, there are large reserves of coalbed methane (CBM) $[1-3]$. CBM can be taken as a kind of resource for comprehensive use $[4,5]$, but it is also a hazardous factor underground, which directly threatens the normal production on the frontline and could easily cause gas explosion [6-8]. Thereby, it should be controlled [9-11], while the exploitation of CBM has always been a research hot spot. However, as a research of basic theory, the pore structure of coal, the methane desorption process, and the mechanism of methane flow in coal seam should be studied first [12].

Coal carries a double-porosity structure [13] full of pores and cracks [14], which have a great influence [15] on the adsorption and desorption of coal body. There are many classification standards about the pores and cracks $[13,16,17]$, but the most widely used criterion in the coal industry of China is the standard of Xodot et al. [18], in which the pores are divided into five types by the pore diameter, and micropores and transition pores are the pores with diameters of $10 \mathrm{~nm}$ and $10 \sim 100 \mathrm{~nm}$, respectively. Research [19] shows that micropores and transitional pores account for more than $80 \%$ of the total pore volume in coal particles, which are the main space for methane adsorption and desorption.

Methane attached to the internal surface of coal pores is the solid state, which constantly exchanges with the gaseous methane molecules in pores. When the adsorption rate is equal to the desorption rate, the exchange reaches a dynamic balance [20]. Once the dynamic equilibrium is destroyed, the gas in pores will begin to flow, which should cause the reduction of interaction force between the internal surface molecules of pores and gas molecules, so the methane molecules in solid state will struggle from the adsorption force of the internal surface, turning into free gaseous molecules in the pore space [21], which forms the process of methane desorption from the coal internal surface. However, the law of the free gas migration and flow in coal body has yet to reach a consensus.

In the early period, most of the scholars agreed that gaseous methane flow in coal seam roughly accords with the Darcy law. Barrer [22] took the linear seepage to describe the gas flowing in coal seam. Later, Zhou and Sun [23] 
believed that the gas flow conformed to the Darcy law in coal seam and put forward the linear gas seepage theory by the seepage mechanics. Based on the theory, an equation of gas seepage was established and preliminarily testified to be correct by the actual test results [24-26]. However, many scholars $[27,28]$ considered that the law of gas flow is diverse in pores with different diameters, i.e., the gas flow obeys molecular diffusion in the small pores but laminar flow in the larger pores and cracks. On this basis, Zhou and Lin [29] established a coalbed structure of the diffusion-seepage model of gas, shown in Figure 1. The coalbed is similar to the brick wall, in which the gas diffuses in the bricks (i.e., the smaller pores). Once into the brickwork joints (i.e., the large pores or cracks), the gas flows outward in filtration. The shape of the brick can be rectangular or round here. Therefore, coalbed can be considered as an object full of globular coal particles, in which micropores and transition pores take up the vast majority of space, and the crack system is between the coal particles. So the laws of methane desorption through coal particles are the fundamental theories for researching the methane flow in coalbed.

Methane emission from the coal particles includes two processes: (1) the desorption of methane molecules from the pore internal surface; (2) the desorbed gas molecules move from the pores to the exterior surface of coal particles. From the molecular motion standpoint, the adsorption or desorption of methane molecules in the pore internal surface is instantaneous, but in fact, the methane escaping from the coal particle needs a certain amount of time, which means the gas flows in the pores should follow certain rules. Yang $[30,31]$ believed that the methane escaping from the coal particles coincided with the Fick diffusion law, i.e., the gas flow rate is proportionate to the gas content gradient, and then, the equation of gas diffusion in coal particles was established. In his paper [30], the theoretical calculating results of the equation accorded with the gas emission measurements. Smith and Williams $[32,33]$ had also presented similar diffusion models. In coal particles, the majority of pores are micropores or transition pores, so most researchers believe that the gas flowing in micropores and transition pores obeys the Fick diffusion law, but in the larger pores, such as mesoporous, macropores, and cracks, it conforms to Darcy's law $[34,35]$. Based on this precondition, some important researches were done. He and Nie [36] and Nie et al. [37] analyzed the gas diffusion modes in coal pores, which included Fick diffusion, Knudsen diffusion, transitional diffusion, surface diffusion, and crystal diffusion, and the transitional diffusion was the main pattern of gas flowing in coal seam. Ruckenstein et al. [38] and Smith and Williams [39] set up a double-pore structure of the spherical diffusion model to explain the gas spreading to the surface of coal particles. However, a lot of experimental results [40, 41] have larger deviation with the theoretical calculation values by the Fick diffusion model.

In the present research, the experiment of methane desorption from coal particle will be carried out, and the mathematical model of methane escaping from spherical coal particles will be established, respectively, based on Fick's law and Darcy's law for the further simulation research. Then,

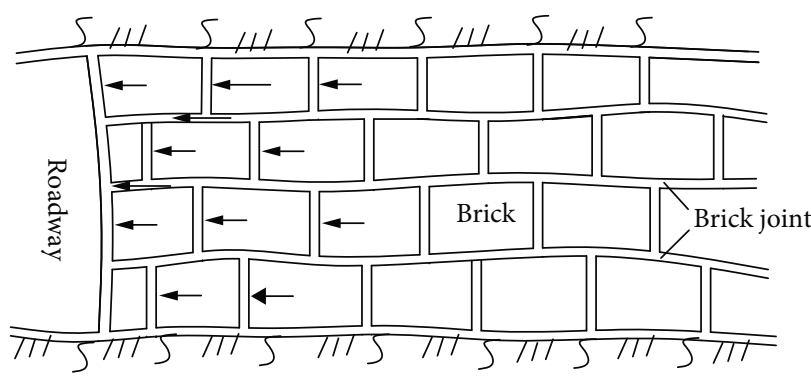

FIGURE 1: Coalbed structure of the diffusion-seepage model of methane.

TABle 1: Particle dimension $(\Phi)$ of coal samples.

\begin{tabular}{lcc}
\hline Coal sample number & Range of mesh & Particle diameter $(\mu \mathrm{m})$ \\
\hline 1 & $4-5$ & $4000-4750$ \\
2 & $15-16$ & $1000-1180$ \\
3 & $30-35$ & $425-550$ \\
4 & $50-60$ & $250-270$ \\
\hline
\end{tabular}

the simulated results will be compared with the experimental results, so as to obtain a more reasonable methane flow pattern in coal particles.

\section{Methane Desorption Experiment from Coal Particle}

2.1. Coal Sample Preparation. The coal samples in our assay came from Yang Caogou Coal Mine, China. In the lab, they were dried in the nitrogen environment at $105^{\circ} \mathrm{C}$. When cooled to room temperature, the samples were crushed to screen out four types of granularities, namely, 4-5 mesh, 15-16 mesh, 30-35 mesh, and 50-60 mesh, so the samples are made up of coal particles, which are considered to be spherical particles. The specific parameters are shown in Table 1.

2.2. Experimental Apparatus and Process. The physical methane desorption includes four types: (1) the reducing pressure desorption; (2) the increasing temperature desorption; (3) the substitution desorption; (4) the diffusion desorption. At the present stage, the depressurization is the main method for the desorption experiment [42], so a reducing pressure desorption system has been used in our experiment, which consisted of the ventilating device, heat regulation system, isothermal adsorption system, and data collection system, as shown in Figure 2. V1 V7 are needle valves, which can be opened or closed by different combinations of valves to complete the relevant operation of the experiment, and $P$ is the pressure sensor used to test the pressure value in the reference tank and sample tank.

Before the experiment, the air tightness of the system was tested. Later, the volume of reference tank and the free space volume of coal sample tank were determined by the vacuum filling helium. At room temperature, the coal sample tank 


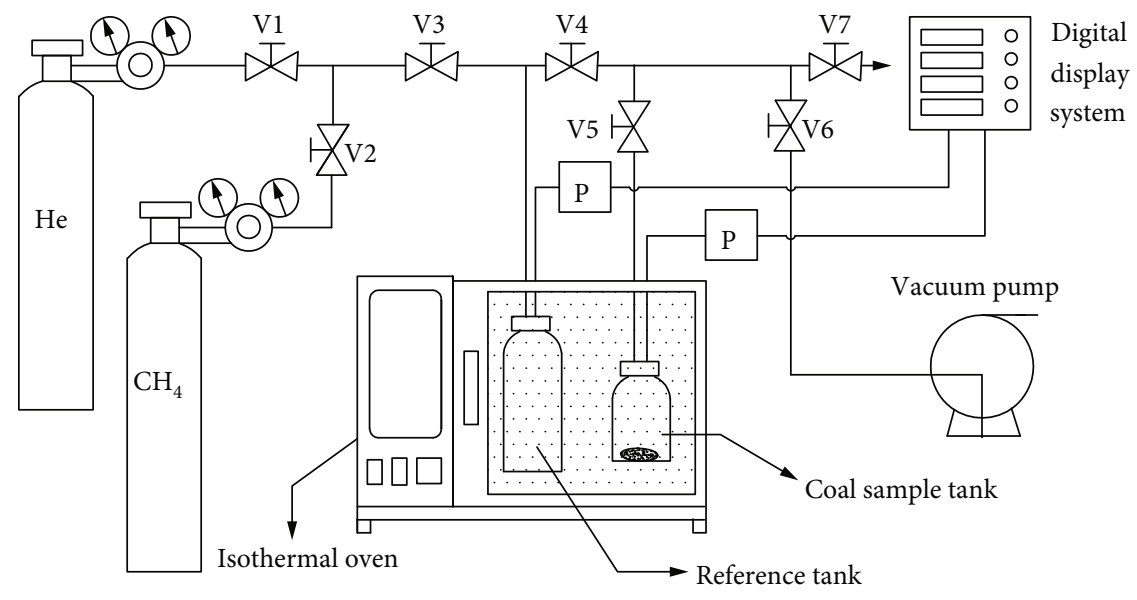

Figure 2: Experiment system schematic view.

underwent vacuum-pumping, and then, a certain pressure of methane, respectively, at $1 \mathrm{MPa}, 2 \mathrm{MPa}$, and $4 \mathrm{MPa}$, was taken into for the coal sample to adsorb sufficiently. When the adsorption reached equilibrium, the desorption experiment began. The pressure in the sample tank is slowly released through the reference tank until it is equal to atmospheric pressure. After that, the coal sample desorption started. If the pressure value of the sample tank rose by $0.01 \mathrm{MPa}$, the operations would be performed to make the pressure of sample tank recover to atmospheric pressure. The same procedure was repeated $N$ times until the end of desorption. In the experiment, the differential pressure value between pre- and postmoments was collected to compute the methane reduction in the free space of coal sample tank, so the methane desorption quantity per unit time can be obtained as

$$
Q_{j}=\frac{p_{j} V_{f}-p_{j-1} V_{f}}{Z G R T_{0} M},
$$

where $Q_{j}$ denotes the methane desorption volume of coal samples at time $j, \mathrm{ml} / \mathrm{g} ; p_{j}, p_{j-1}$ is the methane pressure of the sample tank at time $j, j-1, \mathrm{MPa} ; V_{f}$ denotes the free space volume of sample tank, $\mathrm{ml} ; Z$ refers to the compressibility factor of $\mathrm{CH}_{4}$ at pressure $p_{j}$; $G$ reflects the quality of coal samples, $g ; T_{0}$ denotes the experimental temperature, $\mathrm{K} ; M$ reflects the molar mass of $\mathrm{CH}_{4}, \mathrm{~g} / \mathrm{mol}$.

Therefore, the cumulative methane desorption quantity (CMDQ) can be represented as

$$
Q_{t}=\sum_{j=1}^{t} Q_{j},
$$

in which, $Q_{t}$ denotes the CMDQ in time $t, \mathrm{ml} / \mathrm{g}$.

2.3. Experimental Data Processing and Analysis. Through the experiment, the results of CMDQ of each coal sample at different initial adsorbing pressures were obtained. By analyz- ing, it can be found that the relationship between CMDQ and desorption time accorded with

$$
\frac{1}{Q_{t}}=c_{0} \frac{1}{\sqrt{t}}+d_{0},
$$

where $c_{0}$ and $d_{0}$ are the equation coefficient; $t$ is the desorption time, $\mathrm{h}$.

Here, we define $f(t)$ as time function, $f(t)=1 / \sqrt{t}$, and then to draw out the relationship curves of each case between $1 / Q_{t}$ and $f(t)$ in Figure 3.

From Figure 3, all of the curves between $1 / Q_{t}$ and $f(t)$ are better in linear relationship, and the correlation coefficients $R^{2}$ are all above 0.99 . Therefore, based on formula (3), the theoretical calculation model of CMDQ can be expressed as formula (4), which is similar in the form as the Langmuir equation.

$$
Q_{t}=\frac{A_{0} B_{0} \sqrt{t}}{1+B_{0} \sqrt{t}}
$$

where $A_{0}$ is the ultimate desorption quantity, $A_{0}=1 / d_{0}$, $\mathrm{ml} / \mathrm{g} ; B_{0}$ is a constant to reflect the desorption rate, $B_{0}=$ $d_{0} / c_{0}, 1 / s^{0.5}$. Their values in our experiment are shown in Table 2.

Formula (4) can be used to calculate the CMDQ accurately. The value of $A_{0}$ will not increase unlimitedly, which tends to a constant value when the time increases to infinity, so the $A_{0}$ indicates the maximum methane desorption quantity of coal particles. In Table 2, the greater the initial pressure is, the greater the value of $A_{0}$ becomes, which means that the peak methane desorption volume increases with the initial adsorption pressure rising. However, it seems that the value of $A_{0}$ registers no evident change associated with the coal grain dimension. Some scholars $[43,44]$ believed the reason was that the smaller particle size only increased the outside surface area of coal particle but had no effect on the pore interior surface area which was the main area for methane adsorption. The $B_{0}$ is a physical quantity to reflect the 


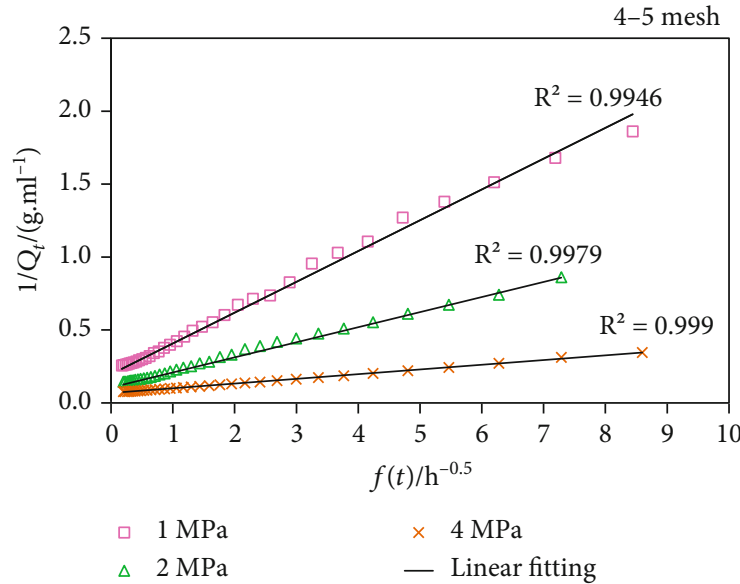

(a)

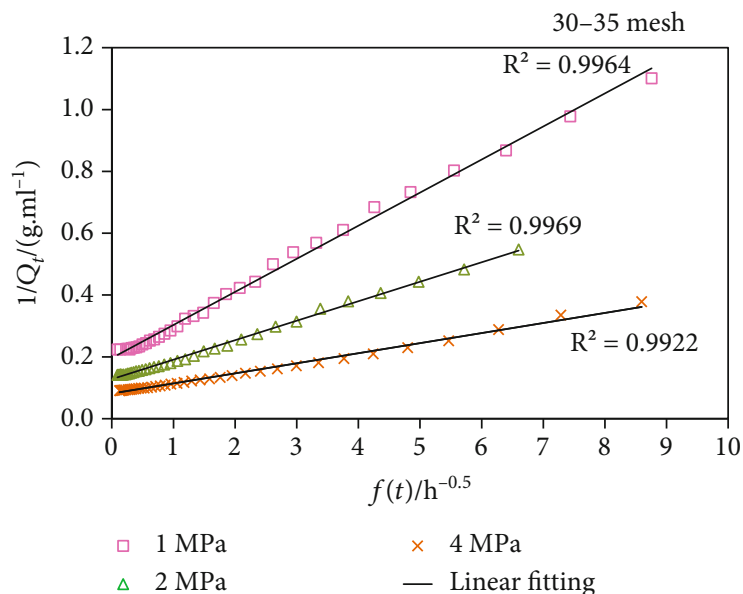

(c)

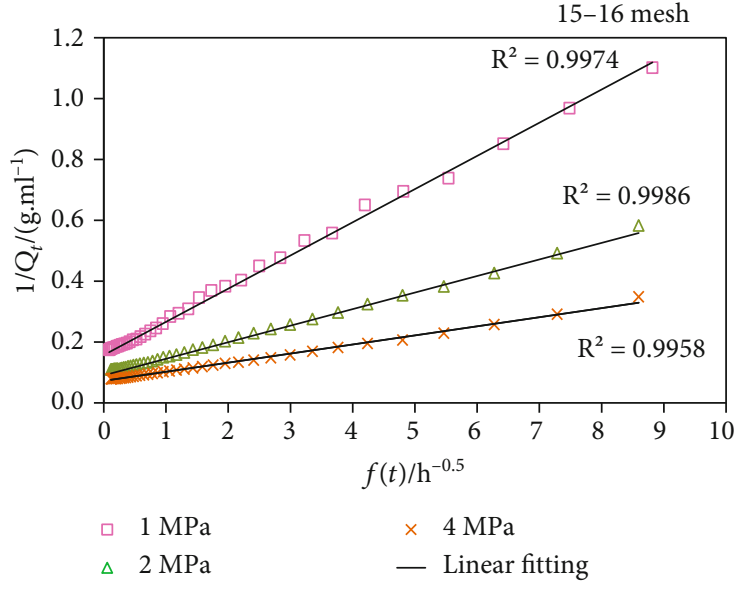

(b)

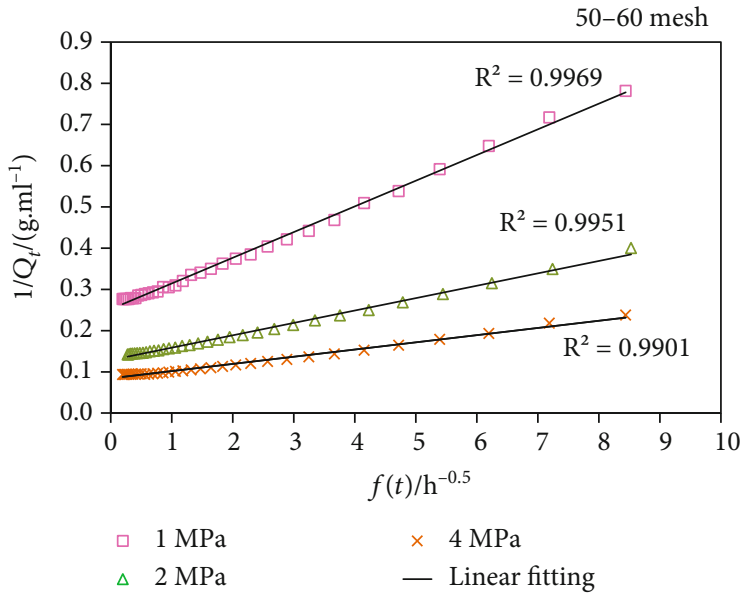

(d)

Figure 3: Curves of $1 / Q$ and $f(t)$ under different initial pressures.

TABle 2: Parameter values of $A_{0}$ and $B_{0}$.

\begin{tabular}{lcccccccc}
\hline \multirow{2}{*}{ Initial pressure (MPa) } & \multicolumn{2}{c}{$4-5$ mesh } & \multicolumn{2}{c}{$15-16$ mesh } & \multicolumn{2}{c}{ 30-35 mesh } & \multicolumn{2}{c}{ mesh } \\
& $A_{0}$ & $B_{0}$ & $A_{0}$ & $B_{0}$ & $A_{0}$ & $A_{0}$ \\
\hline 1 & 5.49 & 0.77 & 7.94 & 0.83 & 5.59 & 1.39 & 4.10 \\
2 & 9.71 & 0.99 & 12.50 & 1.48 & 9.17 & 1.56 & 7.81 \\
4 & 19.23 & 1.63 & 15.38 & 2.24 & 13.69 & 2.81 & 12.05 & 4.41 \\
\hline
\end{tabular}

desorption rate. The experimental results show that the smaller the particle size or the larger the pressure is, the shorter the time of methane desorption to the end will take, so the value of $B_{0}$ is larger.

\section{Fick Diffusion Model}

3.1. The Establishment of the Mathematical Model. Sevenster [45] established the classical methane diffusion mathematical model in coal particle, and the assumptions are as follows: (1) the coal particle is spherical, and there is a large amount of micropore in the coal sphere; (2) the coal particle is homoge- neous and isotropic body; (3) the methane flowing in microporous and transition pores accords with Fick's law.

In Fick's law, the methane diffusion velocity is proportionate to the methane content gradient, but the direction is opposite.

$$
J=-D \frac{\partial X}{\partial \vec{n}}
$$

in which $J$ denotes the diffusion speed, $\mathrm{m}^{3} /\left(\mathrm{m}^{2} \cdot \mathrm{h}\right) ; D$ reflects the methane diffusion coefficient, $\mathrm{m}^{2} / \mathrm{h} ; X$ reflects the 
methane content in per unit volume coal, $\mathrm{m}^{3} / \mathrm{m}^{3} ; \vec{n}$ refers to the diffusion distance in normal direction, $\mathrm{m}$.

The methane diffusion in coal particles is a process of unstable state. In the globular coal particle, the globular shell in the thickness $d r$ is studied. As per the mass conservation law, the methane variable quantity between inflow and outflow of the shell is equivalent to the methane change quantity in the globular shell, so the methane emission equation of coal particle was set up under the spherical coordinates, as follows:

$$
\frac{\partial X}{\partial t}\left[\frac{4}{3} \pi(r+d r)^{3}-\frac{4}{3} \pi r^{3}\right]+\frac{\partial}{\partial r}\left(-D \frac{\partial X}{\partial \vec{n}} \cdot 4 \pi r^{2}\right) d r=0 .
$$

Here, $(d r)^{2} \approx 0,(d r)^{3} \approx 0$, the $D$ is constant, and then, formula (6) can be deduced as

$$
\frac{\partial X}{\partial t}=\frac{D}{r^{2}} \frac{\partial}{\partial r}\left(r^{2} \frac{\partial X}{\partial r}\right)
$$

where $r$ denotes the radius, $\mathrm{m}$.

When desorption begins, the exterior pressure of coal particle is still constant, so the initial conditions and boundary conditions are as follows:

$$
\left\{\begin{array}{l}
X=X_{0}, 0 \leq r \leq R, t=0, \\
\frac{\partial X}{\partial r}=0, r=0, t>0, \\
X=X_{W}, r=R, t>0,
\end{array}\right.
$$

in which $X_{0}$ reflects the initial methane content of coal particle, $\mathrm{m}^{3} / \mathrm{m}^{3} ; X_{W}$ refers to the methane content at surface of coal particles, $\mathrm{m}^{3} / \mathrm{m}^{3} ; R$ reflects the radius of coal particles, $\mathrm{m}$.

3.2. Finite Difference Model. Firstly, the globular coal grain from center to exterior surface is separated into $N$ parts alongside the radius and the intersections are the nodes, documented as $0,1,2,3 \cdots N$, which are expressed as the solid lines in Figure 4. Considering that the variations of pressure, methane content, and diffusion velocity in the center are less than those near the spherical surface, the node spacing from the center to surface declines in a geometric sequence. Secondly, the $N$ homocentric spheres taking the node 0 as circle center are drew in the coal particle, which are through the middle of the two neighboring nodes separately, presented as the dotted lines in Figure 4. So the coal particle is separated into one center solid sphere and $N$ globular shells by the dotted lines.

Apart from the central solid sphere and the globular shell of the $N$ th node, the rest spherical shells all have interior and exterior spherical surfaces, which are through the middle point of the node spacing. So the difference equations of

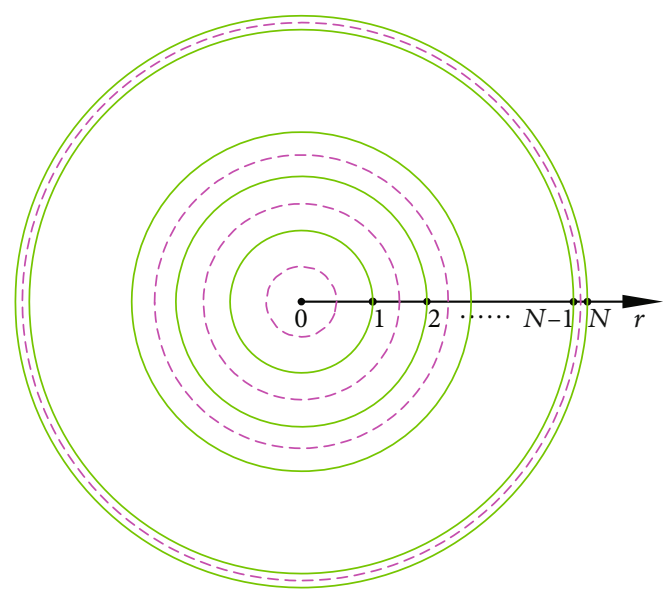

FIGURE 4: Node division under the spherical coordinate system.

unstable flow of methane from 1 to $N-1$ nodes could be considered as follows:

$$
\begin{aligned}
& \frac{4}{3} \pi\left[\left(\frac{r_{i+1}+r_{i}}{2}\right)^{3}-\left(\frac{r_{i-1}+r_{i}}{2}\right)^{3}\right] \times \frac{X_{i}^{j-1}-X_{i}^{j}}{\Delta t_{j}} \\
&=D \frac{\left(\left(\left(X_{i}^{j}-X_{i+1}^{j}\right) / 2\right)+\left(\left(X_{i}^{j-1}-X_{i+1}^{j-1}\right) / 2\right)\right)}{r_{i+1}-r_{i}} \times 4 \pi\left(\frac{r_{i}+r_{i+1}}{2}\right)^{2} \\
&-D \frac{\left(\left(\left(X_{i-1}^{j}-X_{i}^{j}\right) / 2\right)+\left(\left(X_{i-1}^{j-1}-X_{i}^{j-1}\right) / 2\right)\right)}{r_{i}-r_{i-1}} \\
& \times 4 \pi\left(\frac{r_{i}+r_{i-1}}{2}\right)^{2}(i=1,2, \cdots \cdots, N-1 ; j=1,2, \cdots \cdots),
\end{aligned}
$$

in which the subscript $i-1, i$, and $i+1$ denote the node quantity; the superscript $j-1$ and $j$ denote the time node quantity; $\Delta t_{j}$ refers to the time step $j$.

For the center solid sphere, namely, the 0 node, the difference equation is established as follows:

$$
\begin{aligned}
& D \frac{\left(\left(\left(X_{0}^{j}-X_{1}^{j}\right) / 2\right)+\left(\left(X_{0}^{j-1}-X_{1}^{j-1}\right) / 2\right)\right)}{r_{1}} \times 4 \pi\left(\frac{r_{1}}{2}\right)^{2} \\
& \quad=\frac{4}{3} \pi\left(\frac{r_{1}}{2}\right)^{3} \times \frac{X_{0}^{j-1}-X_{0}^{j}}{\Delta t_{j}} .
\end{aligned}
$$

For the $N$ node, which refers to the exterior surface of coal particles, namely, $r=R$, as per the boundary conditions:

$$
X_{N}^{j}=X_{W} .
$$

Formula (9) to (11) forms a complete equation set of the methane flow in coal particles as per Fick's law, in which the methane contents from 0 to $N$ node are the unknown quantities at the $j$ th moment.

After the methane contents of coal particles at each moment are calculated, the methane desorption quantity of spherical coal particle in the $j$ th time step is as 


$$
\Delta Q_{j}=2 \pi R^{2} \Delta t_{j} D \frac{\left(X_{N-1}^{j}+X_{N-1}^{j-1}\right)-\left(X_{N}^{j}+X_{N}^{j-1}\right)}{r_{N}-r_{N-1}} .
$$

The CMDQ of coal particles is the sum of the methane desorption quantity in each time step.

\section{Darcy Percolation Model}

4.1. Establishment of the Mathematical Model. Zhou and Sun [23] proposed the methane emission pattern from coal particles as per Darcy's law, in which the methane pressure, the gas permeability coefficient, and the adsorption constants are the basic influence factors. The assumptions are as follows: (1) the coal particle is spherical, and there is a large amount of micropore and transition pore in the sphere; (2) the porosity and gas permeability coefficient in coal particles are not affected by the internal methane pressure change; (3) the methane absorption satisfies the Langmuir equation, and the free methane is ideal gas. The methane content could be described as follows:

$$
X^{\prime}=\frac{a b p}{1+b p}+B m p
$$

where $X^{\prime}$ denotes the methane content of coal in unit mass, $\mathrm{m}^{3} / \mathrm{t} ; a$ reflects the first adsorption constant, $\mathrm{m}^{3} / \mathrm{t} ; b$ marks the second adsorption constant, $1 / \mathrm{MPa} ; p$ reflects the internal methane pressure of coal body, $\mathrm{MPa} ; B$ denotes the coefficient, $\mathrm{m}^{3} /(\mathrm{t} \cdot \mathrm{Mpa}) ; m$ refers to the porosity.

(4) As the methane flows in coal particles, the temperature is unchanged; (5) the methane flowing in the coal particles is the laminar flow motion, obeying Darcy's law:

$$
u=-\frac{k}{\mu} \nabla p
$$

in which $u$ reflects the velocity of methane flow, $\mathrm{m} / \mathrm{s} ; k$ denotes the permeability of coal seam, $\mathrm{m}^{2} ; \mu$ reflects the gas viscosity coefficient, $\mathrm{MPa} \cdot \mathrm{s} ; \nabla p$ reflects the methane pressure gradient, $\mathrm{MPa} / \mathrm{m}$.

The flowed methane quantity can be determined by the volume flow under one normal atmosphere, so formula (15) can be transformed as

$$
q=-\lambda \frac{\partial P}{\partial \vec{n}}
$$

in which $q$ denotes the methane flow per unit area, $\mathrm{m}^{3} /\left(\mathrm{m}^{2} \cdot \mathrm{s}\right)$; $\lambda$ is the gas permeability coefficient, $\mathrm{m}^{2} /\left(\mathrm{MPa}^{2} \cdot \mathrm{s}\right), \lambda=k / 2 \mu$ $p_{n}, p_{n}$ reflects the standard atmospheric pressure; $P$ is the square of methane pressure, $P=p^{2}, \mathrm{MPa}^{2} ; \vec{n}$ denotes the penetration distance on the normal direction, $m$.

The spherical shell in thickness $d r$ is analyzed in the same way, and the methane emission equation is established as follows:

$$
\frac{\partial X^{\prime}}{\partial t} \rho\left[\frac{4}{3} \pi(r+d r)^{3}-\frac{4}{3} \pi r^{3}\right]+\frac{\partial}{\partial r}\left(-\lambda \frac{\partial P}{\partial r} \cdot 4 \pi r^{2}\right) d r=0
$$

where $\rho$ denotes the apparent density of coal, $\mathrm{t} / \mathrm{m}^{3}$.

Simplification to get

$$
\frac{\partial X^{\prime}}{\partial t}=\frac{\lambda}{\rho}\left(\frac{\partial^{2} P}{\partial r^{2}}+\frac{2}{r} \frac{\partial P}{\partial r}\right)
$$

Taking formula (13) into (17) to get

$$
\frac{\partial(((a b \rho \sqrt{ } P) /(1+b \sqrt{ } P))+B m \rho \sqrt{P})}{\partial t}=\lambda \frac{1}{r^{2}} \frac{\partial}{\partial r}\left(r^{2} \frac{\partial P}{\partial r}\right)
$$

The initial conditions and boundary conditions are as follows:

$$
\left\{\begin{array}{l}
P=P_{0}=p_{0}^{2}, 0 \leq r \leq R, t=0, \\
\frac{\partial P}{\partial r}=0, r=0, t>0, \\
P=P_{W}=p_{w}^{2}, r=R, t>0,
\end{array}\right.
$$

in which $p_{0}$ denotes the initial methane pressure of coal particles, $\mathrm{MPa} ; p_{w}$ reflects the methane pressure at the outside surface of coal particles, MPa.

4.2. Finite Difference Model. In the element division, the Darcy model is the same as the Fick model, shown in Figure 4 . So the difference equations from 1 to $N-1$ nodes are established as

$$
\begin{aligned}
& \lambda \frac{\left(\left(\left(P_{i}^{j}-P_{i+1}^{j}\right) / 2\right)+\left(\left(P_{i}^{j-1}-P_{i+1}^{j-1}\right) / 2\right)\right)}{r_{i+1}-r_{i}} \times 4 \pi\left(\frac{r_{i+1}+r_{i}}{2}\right)^{2} \\
& \quad-\lambda \frac{\left(\left(\left(P_{i-1}^{j}-P_{i}^{j}\right) / 2\right)+\left(\left(P_{i-1}^{j-1}-P_{i}^{j-1}\right) / 2\right)\right)}{r_{i}-r_{i-1}} \\
& \quad \times 4 \pi\left(\frac{r_{i-1}+r_{i}}{2}\right)^{2}=\frac{4}{3} \pi\left[\left(\frac{r_{i+1}+r_{i}}{2}\right)^{3}-\left(\frac{r_{i-1}+r_{i}}{2}\right)^{3}\right] \\
& \quad \times\left[\frac{a b \rho}{2\left(1+b \sqrt{\left(P_{i}^{j}+P_{i}^{j-1}\right) / 2}\right)^{2} \sqrt{\left(P_{i}^{j}+P_{i}^{j-1}\right) / 2}}+\frac{B m \rho}{2 \sqrt{\left(P_{i}^{j}+P_{i}^{j-1}\right) / 2}}\right] \\
& \quad \cdot \frac{P_{i}^{j-1}-P_{i}^{j}}{\Delta t_{j}}(i=1,2, \cdots \cdots, N-1 ; j=1,2, \cdots \cdots) .
\end{aligned}
$$

As to the spherical center point, the difference equation is expressed as follows: 


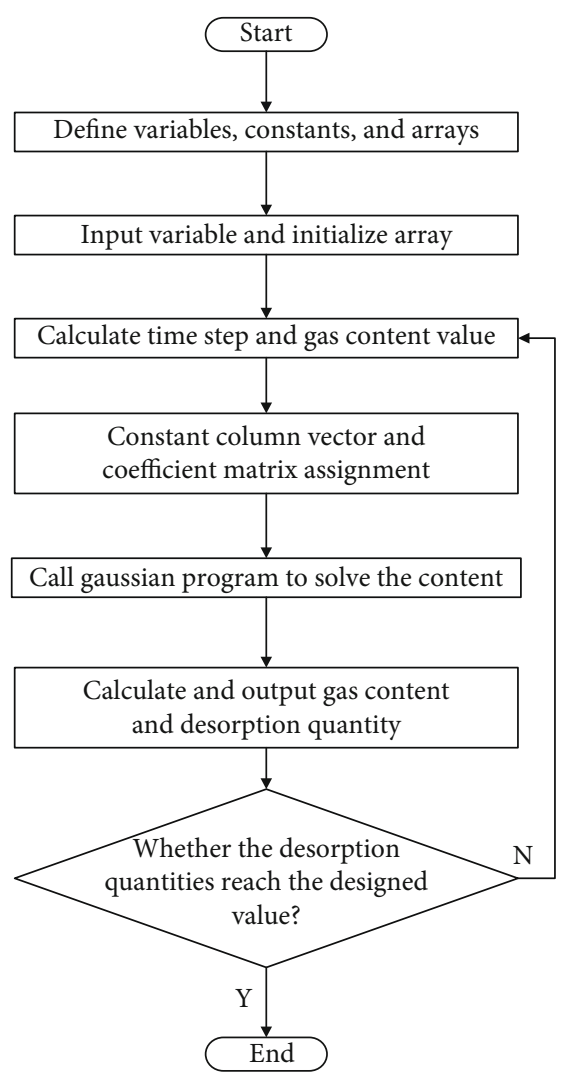

(a) Fick model

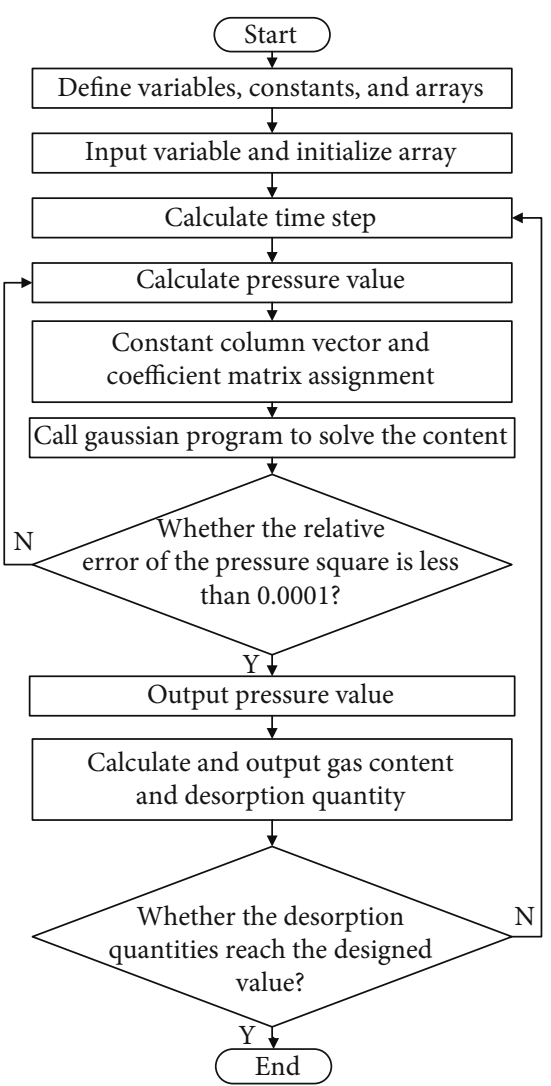

(b) Darcy model

Figure 5: Flowchart of program structure.

$$
\begin{aligned}
& \lambda \frac{\left(\left(P_{0}^{j}-P_{1}^{j}\right) / 2\right)+\left(\left(P_{0}^{j-1}-P_{1}^{j-1}\right) / 2\right)}{r_{1}} \times 4 \pi\left(\frac{r_{1}}{2}\right)^{2} \\
& \quad=\frac{4}{3} \pi\left(\frac{r_{1}}{2}\right)^{3} \times\left[\frac{a b \rho}{2\left(1+b \sqrt{\left(P_{0}^{j}+P_{0}^{j-1}\right) / 2}\right)^{2} \sqrt{\left(P_{0}^{j}+P_{0}^{j-1}\right) / 2}}\right. \\
& \left.+\frac{B m \rho}{2 \sqrt{\left(P_{0}^{j}+P_{0}^{j-1}\right) / 2}}\right] \frac{P_{0}^{j-1}-P_{0}^{j}}{\Delta t_{j}} .
\end{aligned}
$$

As to the exterior surface, namely, $r=R$, according to the boundary conditions:

$$
P_{N}^{j}=P_{W}
$$

Formula (20) to (22) forms a complete equation set of the methane flow in coal particles as per Darcy's law, in which the methane pressures from 0 to $N$ node are the unknown quantities at the $j$ th moment.

After the methane pressure square at each moment is calculated, the methane desorption quantity of coal particles in the $j$ th time step is as

$$
\Delta Q_{j}=2 \pi R^{2} \Delta t_{j} \lambda \frac{\left(P_{N-1}^{j}+P_{N-1}^{j-1}\right)-\left(P_{N}^{j}+P_{N}^{j-1}\right)}{r_{N}-r_{N-1}} .
$$

The CMDQ of coal particle is the sum of the methane desorption quantity in each time step.

\section{Programming and Operation}

Based on the above difference model and boundary conditions, the corresponding calculating software is designed and compiled.

For the Fick diffusion difference model, the content is unknown. In the process of calculating, given a time step and the eventual methane content, the following methane content could be computed. By analogy, the methane content value at each time node can be obtained. Due to the methane desorption rate diminishing with time prolonging, the time step in calculation increases according to a geometric sequence which gradually enlarges. In this way, the calculated time is saved but the calculated precision is still high. The program structure process is shown in Figure 5(a).

For the Darcy percolation differential model, the square of methane pressure is unknown. In calculating, given a time step and the eventual pressure, the following pressure could be obtained. The methane pressure in the coal particle 


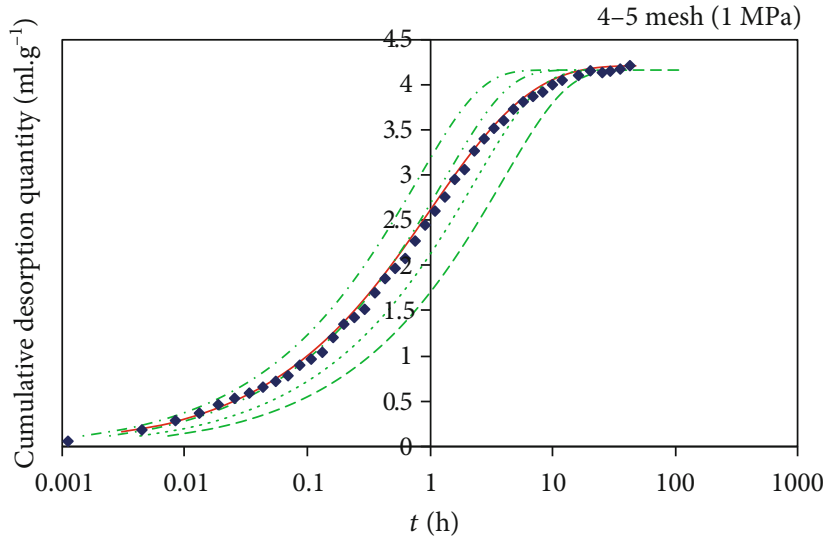

- Measured

- Simulated (Darcy)

- $\mathrm{D}=0.0000003$ (Fick)

(a)

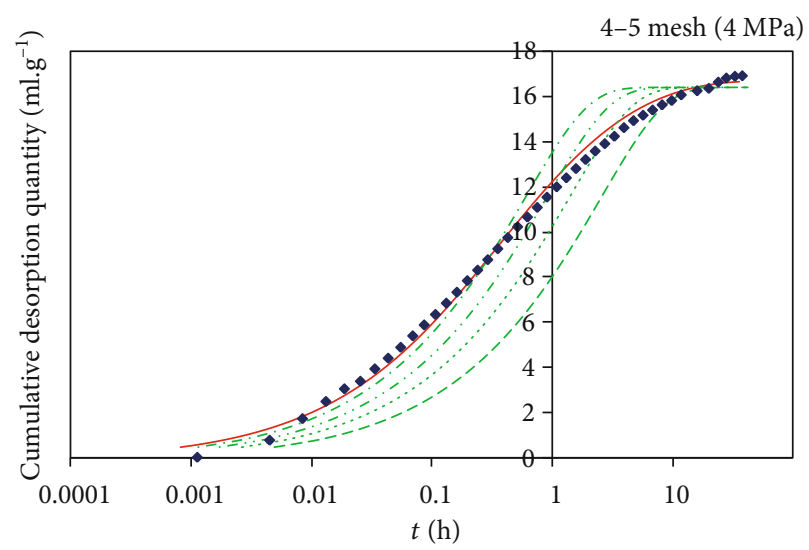

- Measured

- … $\mathrm{D}=0.0000013$ (Fick)

_ Simulated (Darcy)

- - $\mathrm{D}=0.0000007$ (Fick)

$$
\mathrm{D}=0.0000020 \text { (Fick) }
$$$$
\text { . . - } \mathrm{D}=0.0000030 \text { (Fick) }
$$

(c)

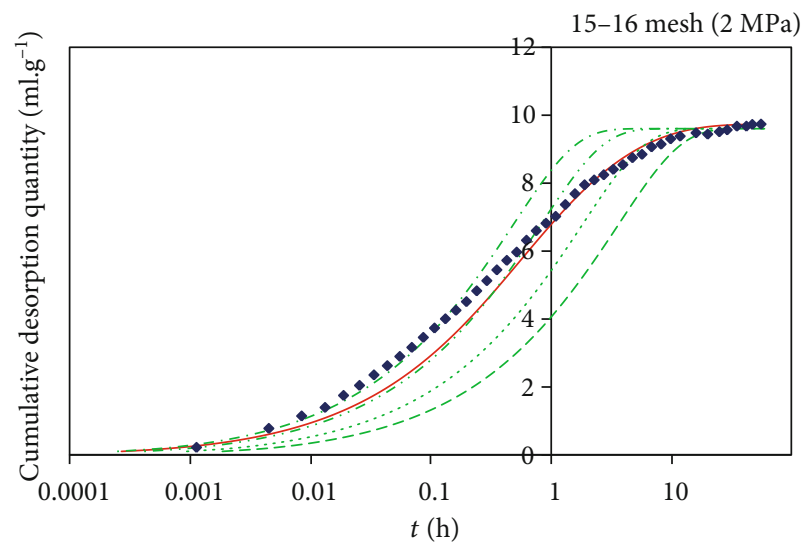

$\begin{array}{ll}- \text { Measured } & \cdots \cdots \mathrm{D}=0.00000004 \text { (Fick) } \\ - \text { Simulated (Darcy) } & \cdots \cdots \mathrm{D}=0.00000009 \text { (Fick) } \\ ---\mathrm{D}=0.00000002 \text { (Fick) } & \cdots \cdot \mathrm{D}=0.00000015 \text { (Fick) }\end{array}$

(e)

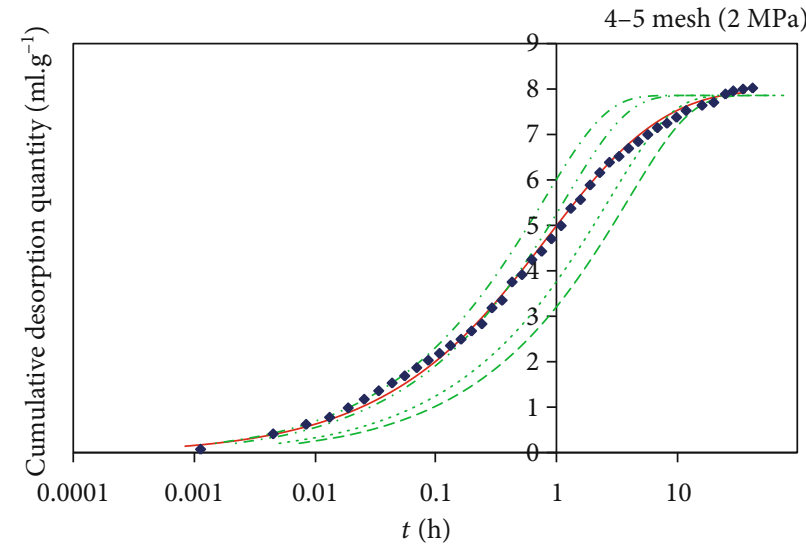

- Measured

- ‥ D $=0.0000004$ (Fick)

- Simulated (Darcy)

$\mathrm{D}=0.0000010$ (Fick)

- - $\quad \mathrm{D}=0.0000003$ (Fick)

. . - $\mathrm{D}=0.0000015$ (Fick)

(b)

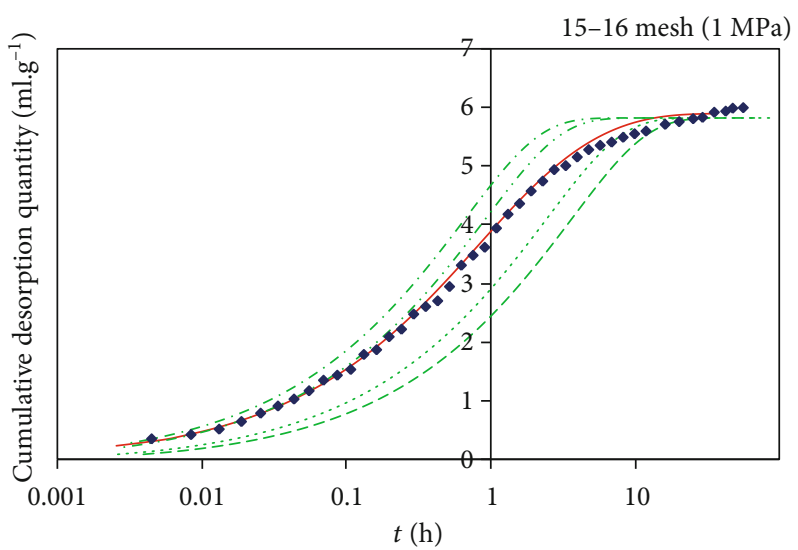

- Measured

- … D $=0.00000003$ (Fick)

— Simulated (Darcy)

…. $\mathrm{D}=0.00000008$ (Fick)

- - $\mathrm{D}=0.00000002$ (Fick)

- . $-\mathrm{D}=0.00000011$ (Fick)

(d)

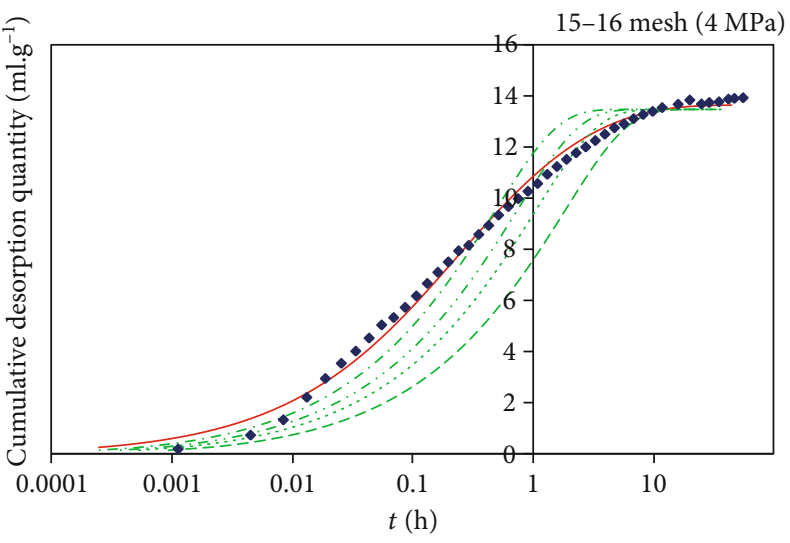

$\begin{array}{ll}\text { Measured } & -\cdots \mathrm{D}=0.00000007 \text { (Fick) } \\ - \text { Simulated (Darcy) } & \cdots \cdots \mathrm{D}=0.00000010 \text { (Fick) } \\ ---\mathrm{D}=0.00000004 \text { (Fick) } & -\cdots \mathrm{D}=0.00000015 \text { (Fick) }\end{array}$

(f)

Figure 6: Continued. 


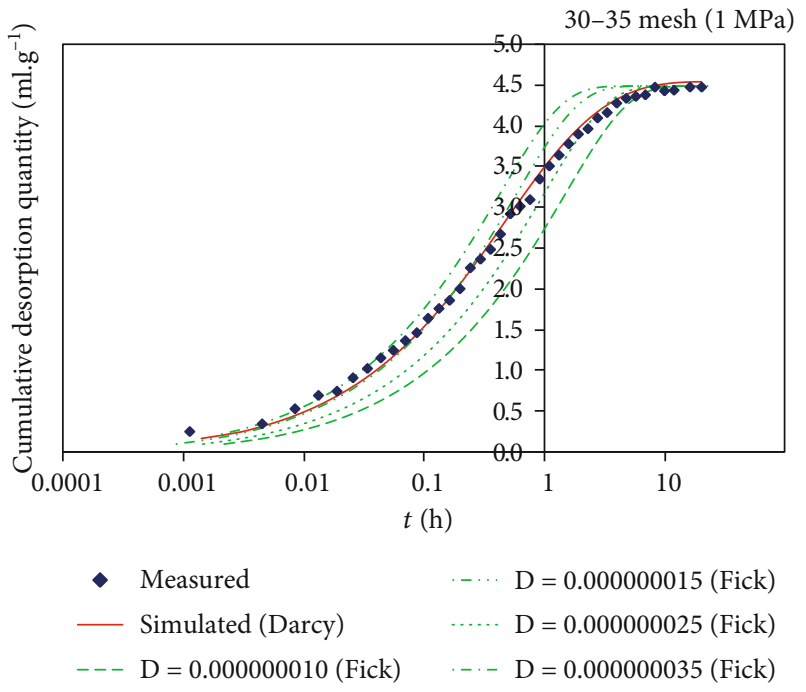

(g)

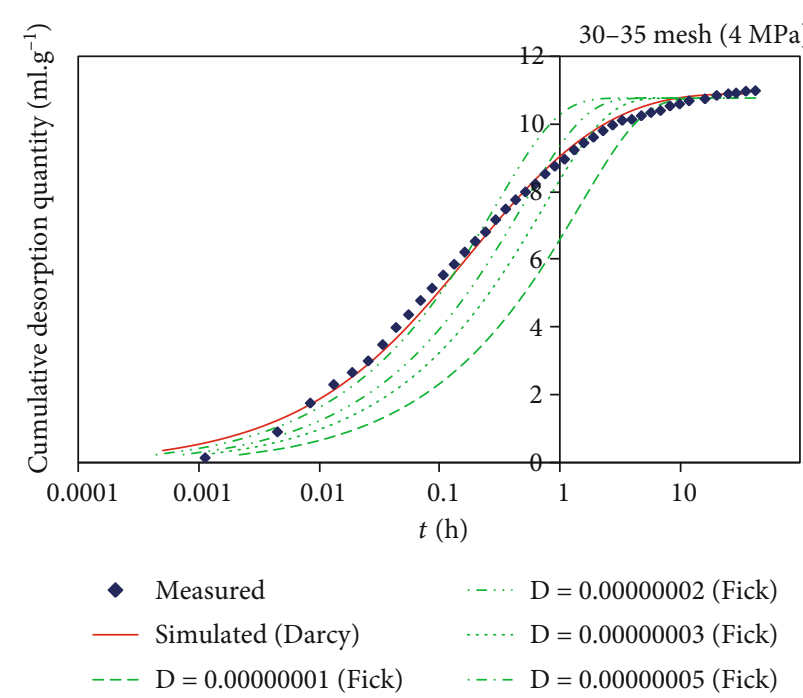

(i)

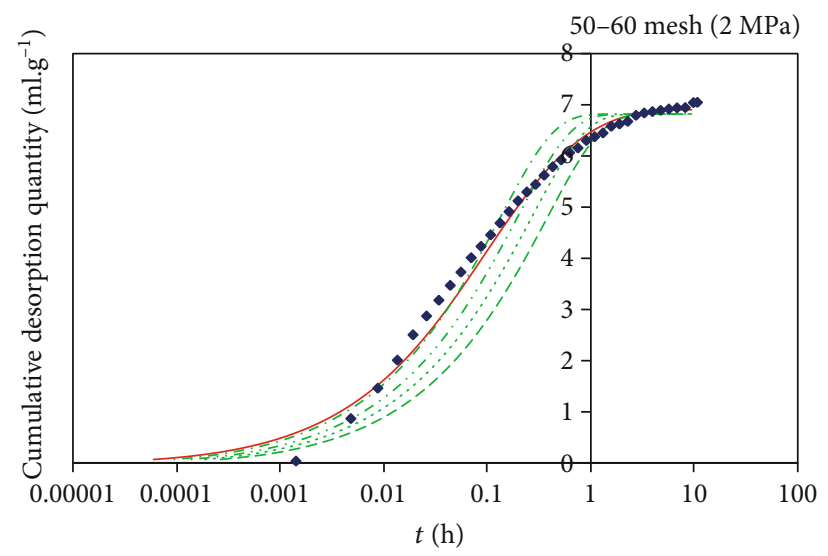

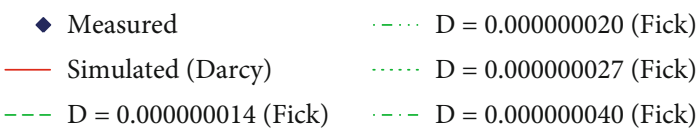

(k)

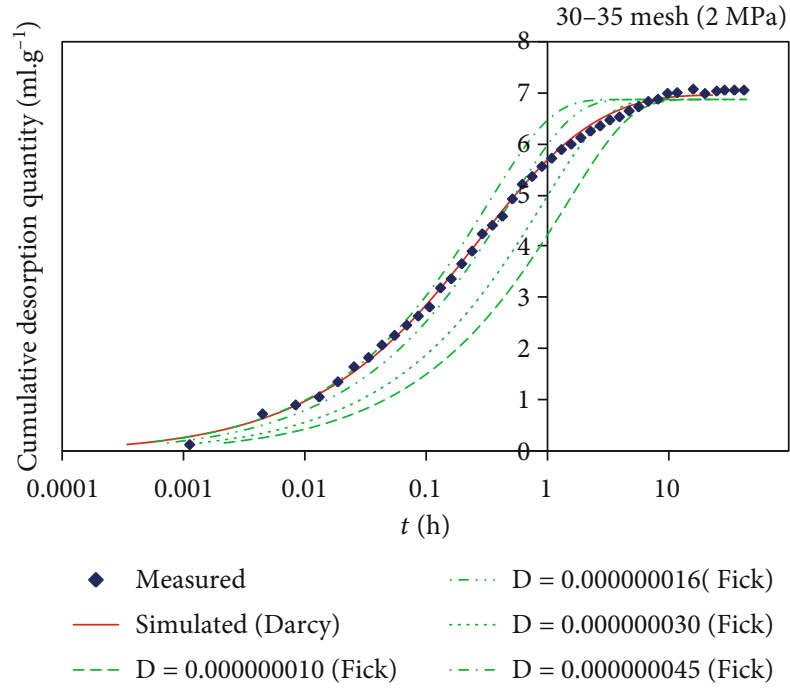

(h)

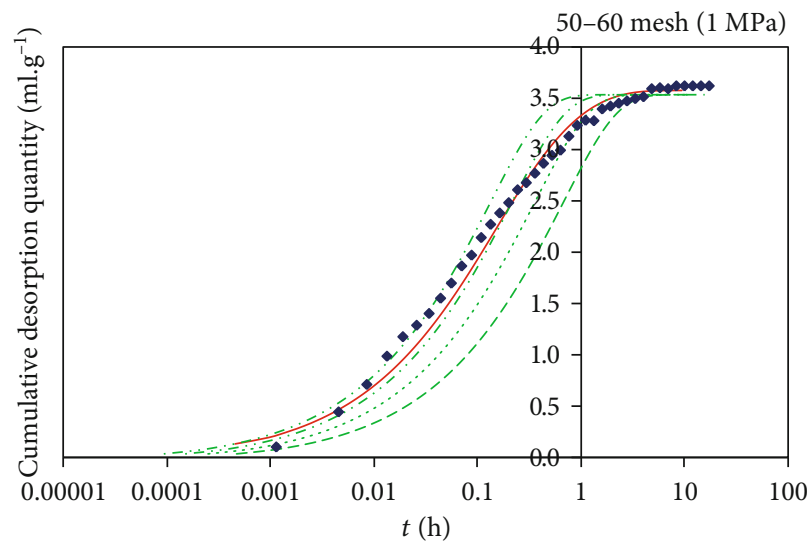

- Measured

$\mathrm{D}=0.000000015$ (Fick)

- Simulated (Darcy)

$\mathrm{D}=0.000000025$ (Fick)

- - - D $=0.000000008$ (Fick)

-. - $\mathrm{D}=0.000000040$ (Fick)

(j)

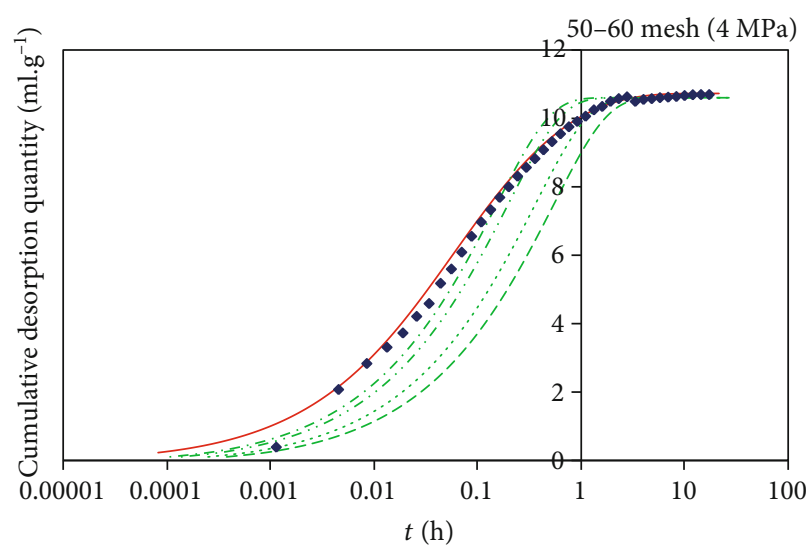
- Measured
$\mathrm{D}=0.000000015$ (Fick)
Simulated (Darcy)
…. $\mathrm{D}=0.000000027$ (Fick)
- - $\mathrm{D}=0.000000010$ (Fick)
$\mathrm{D}=0.000000035$ (Fick)

(l)

FIgURE 6: Contrast curves between simulated CMDQ and experimental CMDQ. 


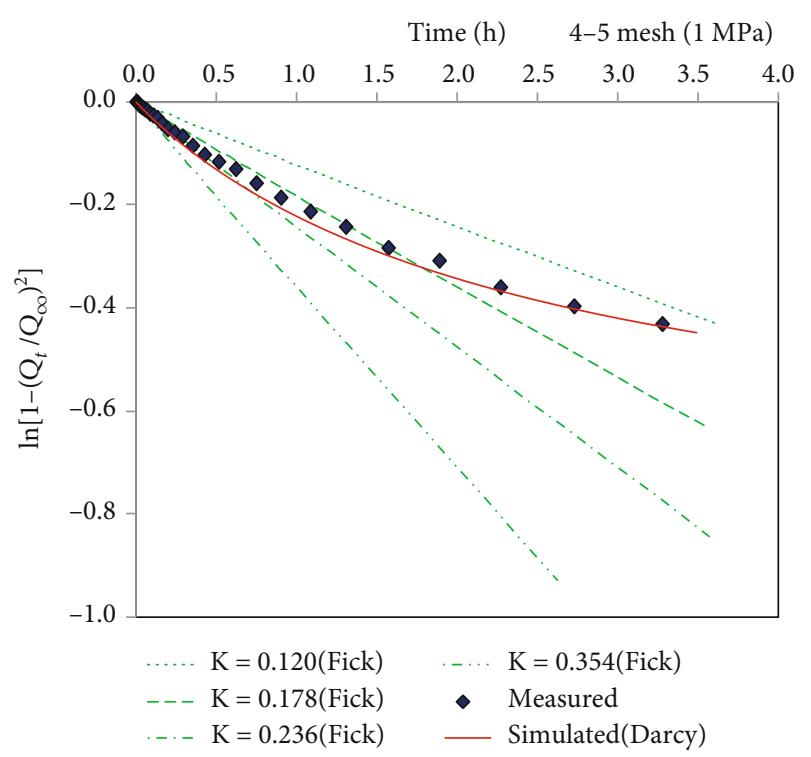

(a)

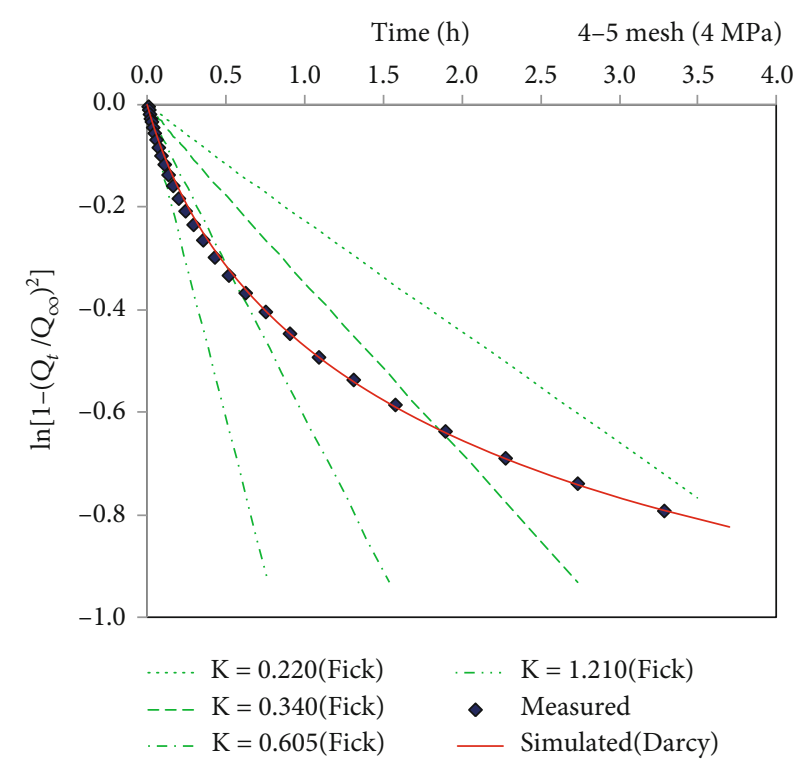

(c)

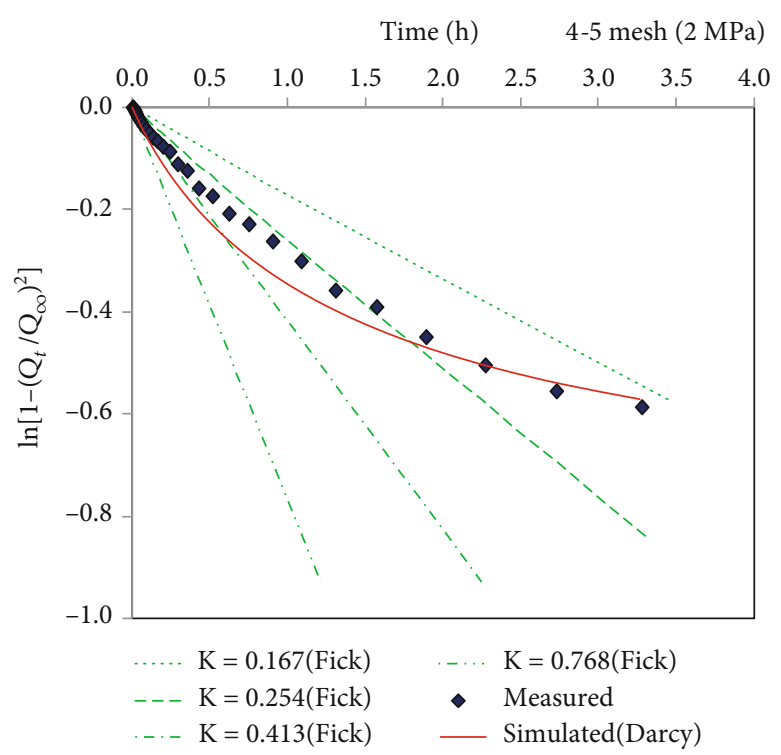

(b)

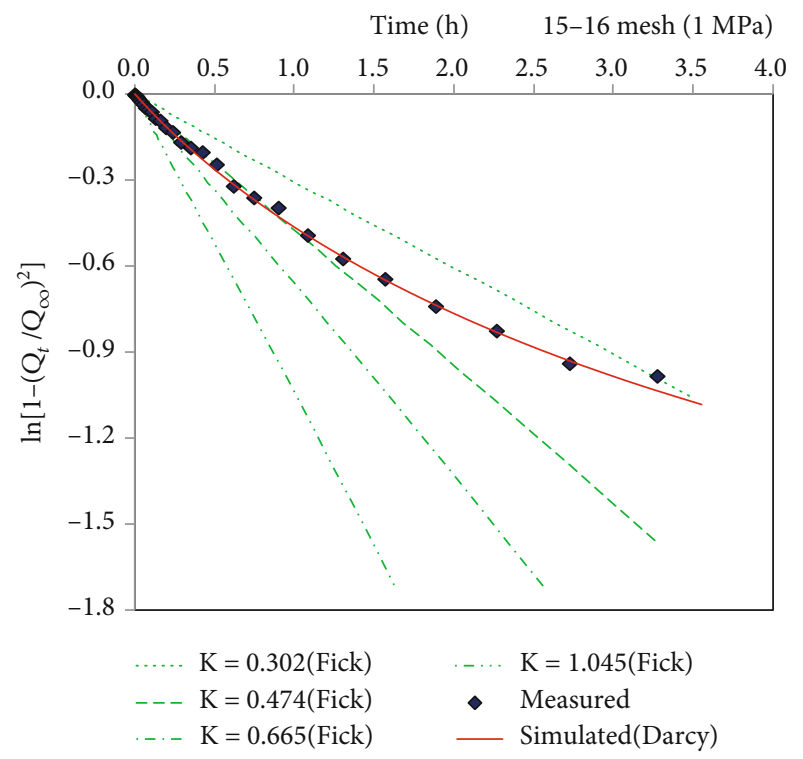

(d)

FIgure 7: Continued. 


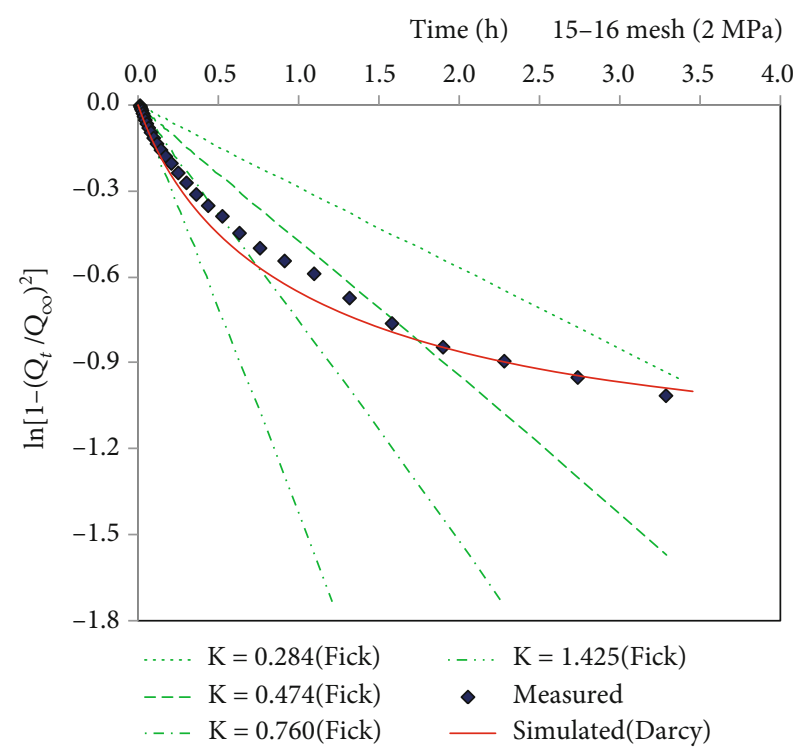

(e)

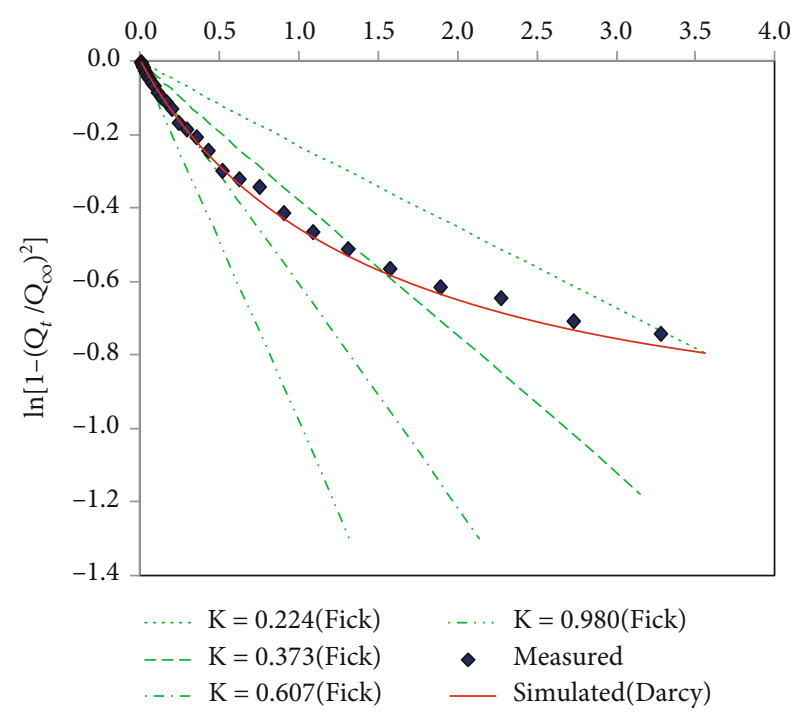

(g)

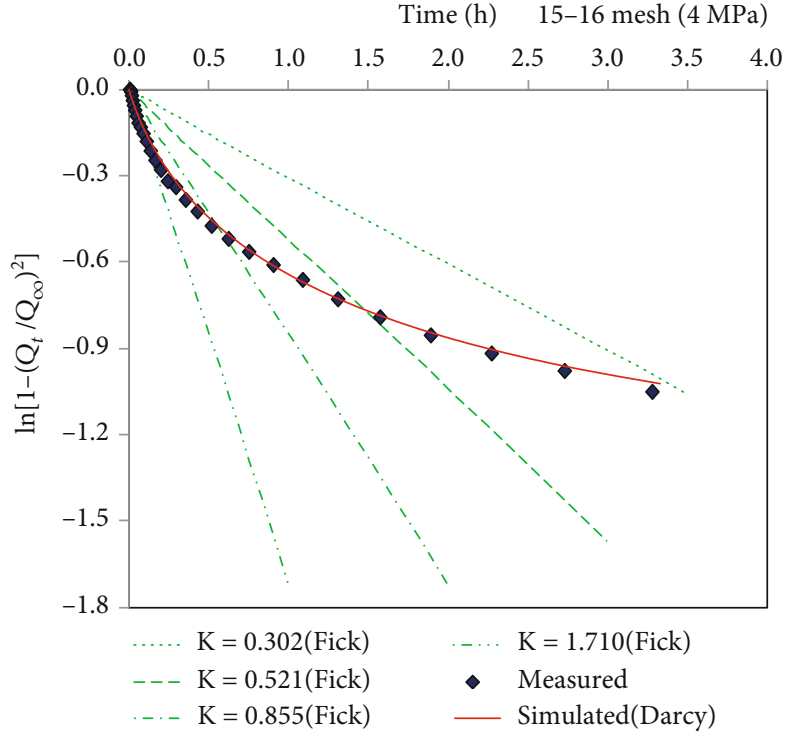

(f)

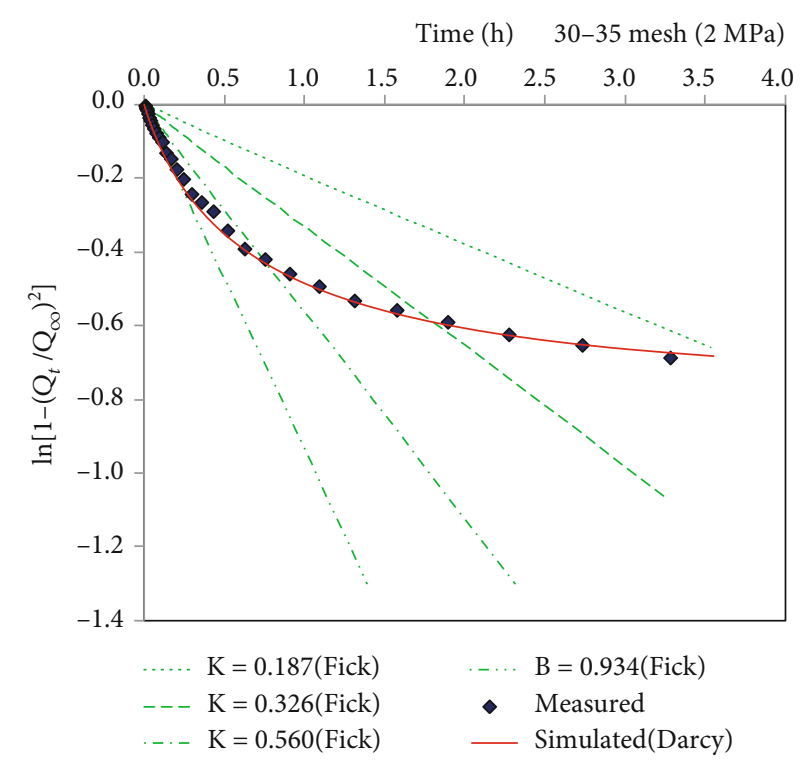

(h)

Figure 7: Continued. 


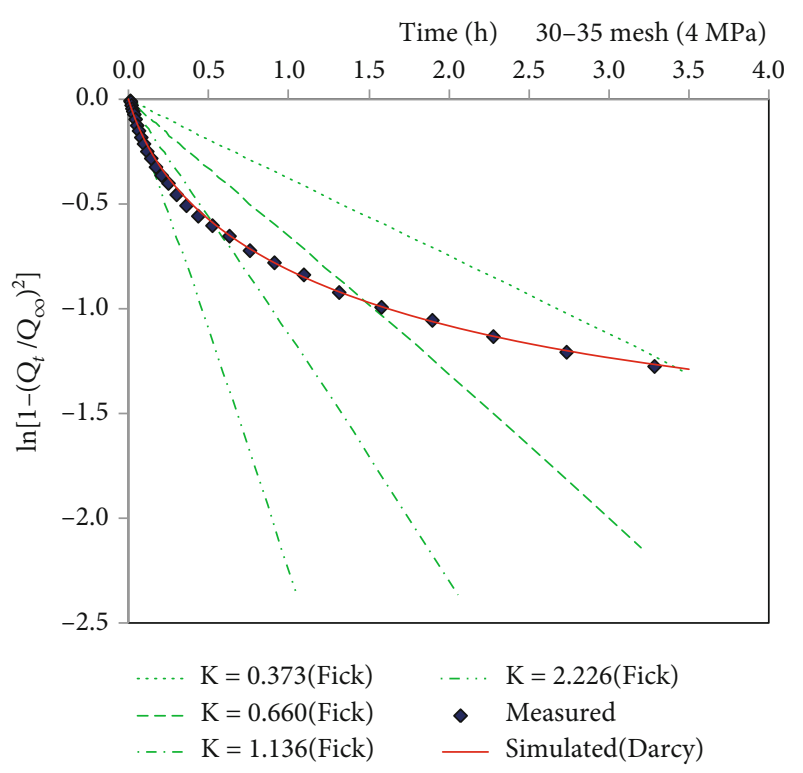

(i)

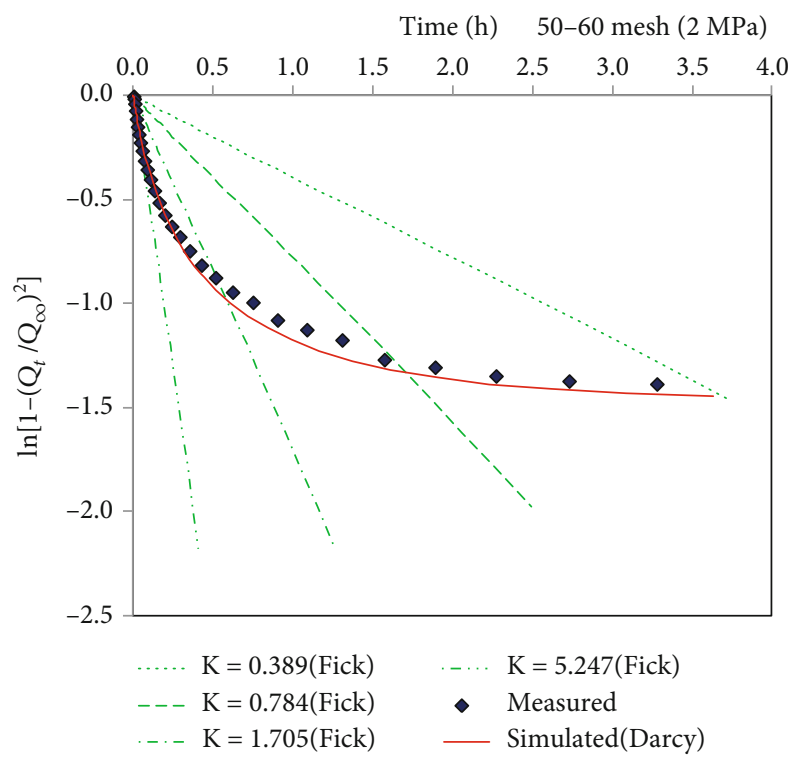

(k)

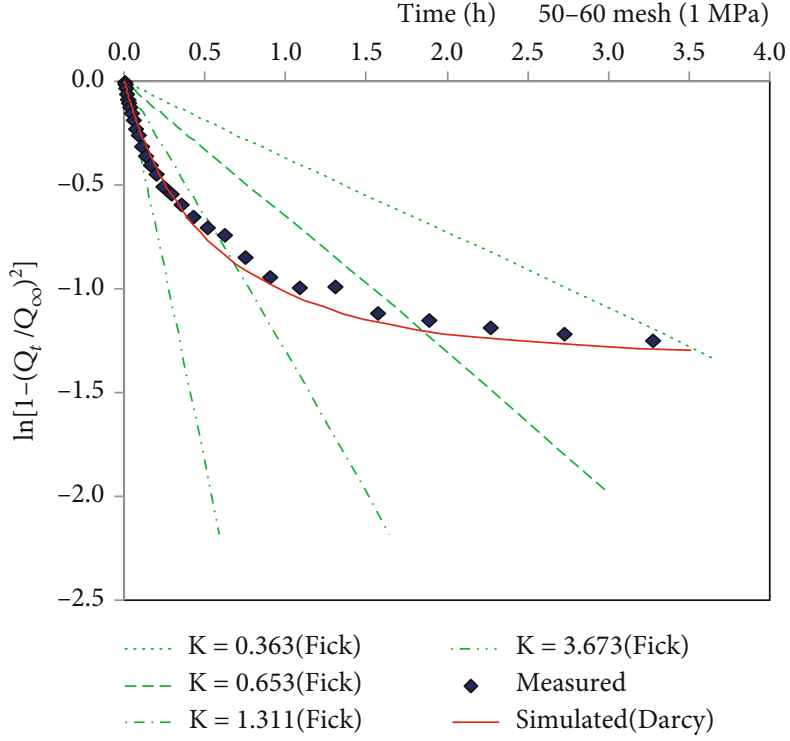

(j)

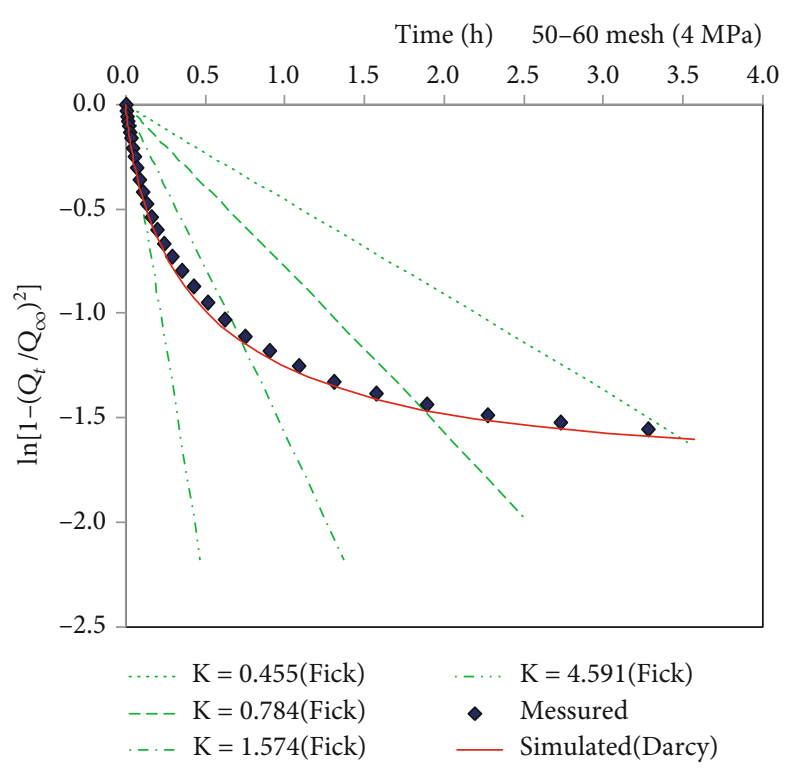

(l)

FIGURE 7: Contrast curves between simulation and experimental MERF.

can be calculated at any time, and the time step also uses a geometric progression step length. The right side of formulas (20) and (21) is the nonlinear expression of the node's pressure square at the $j$ th moment, so the iteration method should be used. Assumed $P_{i}{ }^{j}=c P_{i}{ }^{j-1}$, the numerical value under the square root is calculated to get quasilinear equations and the solution, and then, the solution is employed to compute the value under the square root, so new quasilinear equations and the new solution should be obtained again. We repeat the calculation until the relative error of the pre- and postcomputational value is less than a small value. The program structure process is shown in Figure 5(b).

\section{Comparative Analyses between the Simulated and Experimental Results}

In the Darcy model, the methane adsorption parameters and the porosity of coal derived from the relevant experimental results where $a$ is $26 \mathrm{~m}^{3} / \mathrm{t}, b$ is $0.3 \mathrm{MPa}^{-1}, m$ is 0.5 , and $\rho$ is $1.2 \mathrm{~m}^{3} / \mathrm{t}$. Through the trial calculation, when the gas permeability coefficient is at $1 \times 10^{-5} \mathrm{~m}^{2} /\left(\mathrm{MPa}^{2} \cdot \mathrm{s}\right)$, the simulated results of CMDQ fit better with the experimental results. For the Fick model, if the coal particle radius, the initial methane pressure, and content are given, the diffusion coefficient $D$ will be the only influence factor for the methane desorption, and its scope of the trial calculation is taken 
from $2 \times 10^{-9}$ to $2 \times 10^{-5} \mathrm{~m}^{3} /\left(\mathrm{m}^{2} \cdot \mathrm{d}\right)$. So when the exterior pressure of coal particles is at a normal atmosphere, the variation processes of CMDQ of different coal samples can be calculated, and the results will be compared with the experimental results.

6.1. Comparison of CMDQ. Figure 6 shows the curves of the experiment and simulation of each coal sample under different initial pressures. In order to observe the matching degree of curves more easily, the logarithmic coordinate is used in the figure.

It can be concluded from Figure 6 (1) that the variation trend of Darcy's simulated results is basically identical to the experimental results, but Fick's results have large difference; (2) Darcy's results are pretty consistent with the experimental results in most time, and the differences mainly appear in the initial period. This is because limited by the experimental conditions, the external pressure of coal particles cannot realize the constant pressure in the initial phase; (3) when the diffusion coefficient $D$ becomes larger, Fick's results are more close to the experimental results in the initial stage, but the simulated results reach the desorption balance earlier than that of the experiment, so great deviations emerge later. It indicates that no matter how the $D$ changes, Fick's curves do not always match well with the experimental curves.

6.2. Comparison of Methane Emission Rate Function. Yang and Wang [46] put forward the methane emission rate function (MERF), which was expressed as $\ln \left[1-\left(Q_{t} / Q_{\infty}\right)^{2}\right]$. In their paper, the methane emission rates of six kinds of particle size of coal samples were studied by Fick's law to obtain that MERF registered linear change with time $t$.

$$
\frac{\ln \left[1-\left(Q_{t} / Q_{\infty}\right)^{2}\right]}{t}=-K,
$$

where $Q_{\infty}$ is the CMDQ when $t$ tends to infinity, $\mathrm{ml} / \mathrm{g} ;-K$ is the slope of MERF with $t$.

The change rules between MERF and $t$ are studied, respectively, under Fick's diffusion, Darcy's seepage, and the experimental measure. The simulated and measured data are processed and shown in Figure 7. Here, the values of $Q_{\infty}$ take the $A_{0}$ in Section 2.3.

From Figure 7, (1) the MERF of Darcy's simulation are all curving changes as the time increases, which have the similar variation trend to the experiment, but all of Fick's MERF are growth in straight lines over time; (2) Darcy's simulation results mostly accord with the experimental results; (3) Fick's simulated results are only close to the measured results at the initial stage and appear deviation later, in which the gap became larger and larger as time increases. No matter how the $D$ changes, the curves of Fick's results register linear variation and cannot match well with the experimental curves.

\section{Discussion}

The CMDQ of Fick's simulation, Darcy's simulation, and experimental measure are compared to show that Darcy' results highly agree with the experimental results. While no matter how we change the size of the methane diffusion coefficient $D$, the curves of CMDQ in Fick diffusion can never well accord with the experimental curve. This indicates that the methane emission process in coal particles is more accordant with Darcy's law. For the theory analysis, the vast majority of methane is adsorbed at the pore internal surface of coal particle, which is relatively static and almost without flow. So the movement of free methane gas becomes the main form for methane flowing in coal particles, and its flow velocity exhibits no direct association with methane content but is closely related to the gas pressure gradient. Therefore, the methane flow in coal particles should accord with Darcy's law.

The change law of MERF in coal particles is also analyzed in this paper and shows that the experimental MERF are all curving changes with the time growing. The literature [41] also obtained the same experimental conclusion. The MERF under Darcy's condition are also curving change and coincident with the experimental results. However, the MERF under Fick's condition linearly change as time increases and obviously do not follow the measured trends, which indicates that the methane emission from coal particles should not conform to Fick's law, and at least, the situation that the diffusion coefficient $D$ is constant in methane emission can be excluded. From the mechanism of methane emission, in the early emission period, the emitted methane is primarily from the outside surface or the macropores of coal particles, flowing out rapidly, so the emission quantity is fast. But, later, emission source mainly comes from the internal surface of microporous and transition pores. As the diameter of these pores is smaller, the path becomes lengthier and the resistance is also greater, which decreases the emission quantity gradually. Therefore, in the process of the methane emission from coal particle, the MERF will not change linearly, so some scholars [12, 47] believed the methane diffusion coefficient in coal particles is attenuated over time, which still needs a further research.

\section{Conclusions}

(1) The methane isothermal desorption experiment of coal particles was performed to obtain that the relationship between the reciprocal of cumulative methane desorption quantity (CMDQ) and the reciprocal of square root of time was linear, and the correlation coefficients $R^{2}$ are all above 0.99 . The basis on the experiment, an empirical formula of CMDQ was given, which can be used to calculate the CMDQ accurately

(2) The methane flow mathematic models of spherical coal particle were established, respectively, according to Fick diffusion law and Darcy percolation law. The corresponding calculating software was programmed with the finite difference method. By the software, the simulated CMDQ and the calculated methane emission rate function (MERF) of the two models were obtained under different initial adsorption pressures 
(3) Comparative analyses between the simulation results and the assay outcomes indicate that Darcy's simulated outcomes are consistent with the experimental results, whereas all Fick's results, no matter how the diffusion coefficient changes, have a comparatively large difference from the experimental data. Therefore, the studies in this paper show that the methane flow obeys Darcy's law even in the tiny pore system of coal particles, which provides the basis for further study on the law of methane flow in coalbed

\section{Data Availability}

The data used to support the findings of this study are available from the corresponding author upon request.

\section{Conflicts of Interest}

The authors declare that they have no conflicts of interest.

\section{Acknowledgments}

The research is financially supported by the Applied Basic Research Plan of Shanxi Province (No. 201901D211294) and Universities Science and Technology Innovation Project in Shanxi Province (No. 2020L0365).

\section{References}

[1] C. J. Bibler, J. S. Marshall, and R. C. Pilcher, "Status of worldwide coal mine methane emissions and use," International Journal of Coal Geology, vol. 35, no. 1-4, pp. 283-310, 1998.

[2] P. Liu, J. Fan, D. Jiang, and J. Li, "Evaluation of underground coal gas drainage performance: mine site measurements and parametric sensitivity analysis," Process Safety and Environmental Protection, vol. 148, pp. 711-723, 2021.

[3] T. A. Moore, "Coalbed methane: a review," International Journal of Coal Geology, vol. 101, no. 1, pp. 36-81, 2012.

[4] S. Su, A. Beath, H. Guo, and C. Mallett, "An assessment of mine methane mitigation and utilisation technologies," Progress in Energy and Combustion Science, vol. 31, no. 2, pp. 123-170, 2005.

[5] P. Liu, A. Liu, F. Zhong, Y. Jiang, and J. Li, "Pore/fracture structure and gas permeability alterations induced by ultrasound treatment in coal and its application to enhanced coalbed methane recovery," Journal of Petroleum Science and Engineering, vol. 205, pp. 108862-108877, 2021.

[6] X. P. Yuan, "The characters and trend of accidents in the coal mining in China," Disaster Advances, vol. 86, no. 2-3, pp. 867870, 2012.

[7] A. Liu, P. Liu, and S. M. Liu, "Gas diffusion coefficient estimation of coal: a dimensionless numerical method and its experimental validation," International Journal of Heat and Mass Transfer, vol. 162, pp. 120336-120351, 2020.

[8] Q. Ye, Z. Z. Jia, and H. Z. Wang, "Characteristics and control technology of gas explosion in gob of coal mines," Disaster Advances, vol. 86, no. 2-3, pp. 112-118, 2013.

[9] R. M. Flores, "Coalbed methane: from hazard to resource," International Journal of Coal Geology, vol. 35, no. 1-4, pp. 326, 1998 .
[10] C. Ö. Karacan, "Modeling and prediction of ventilation methane emissions of U.S. longwall mines using supervised artificial neural networks," International Journal of Coal Geology, vol. 73, no. 3-4, pp. 371-387, 2008.

[11] C. Ö. Karacan, "Forecasting gob gas venthole production performances using intelligent computing methods for optimum methane control in longwall coal mines," International Journal of Coal Geology, vol. 79, no. 4, pp. 131-144, 2009.

[12] A. D. Alexeev, E. P. Feldman, and T. A. Vasilenko, "Methane desorption from a coal-bed," Fuel, vol. 86, no. 16, pp. 25742580, 2007.

[13] H. Gan, S. P. Nandi, and P. L. Walker, "Nature of the porosity in American coals," Fuel, vol. 51, no. 4, pp. 272-277, 1972.

[14] S. Harpalani and G. L. Chen, "Estimation of changes in fracture porosity of coal with gas emission," Fuel, vol. 74, no. 10, pp. 1491-1498, 1995.

[15] G. Amarasekera, M. J. Scarlett, and D. E. Mainwaring, "Micropore size distributions and specific interactions in coals," Fuel, vol. 74, no. 1, pp. 115-118, 1995.

[16] P. C. Kearney, "International Union of Pure and Applied Chemistry," Pure and Applied Chemistry, vol. 13, pp. 499500, 1955.

[17] C. R. Clarkson and M. R. Bustin, "Variation in micropore capacity and size distribution with composition in bituminous coal of the Western Canadian Sedimentary Basin: implications for coalbed methane potential," Fuel, vol. 75, no. 13, pp. 14831498, 1996.

[18] B. B. Xodot, S. Z. Song, and Y. A. Wang, Coal and Gas Outburst, China Industrial Press, Beijing, China, 1966.

[19] G. Liu, Z. Zhang, X. Zhang, and R. S. Lu, "Pore distribution regularity and absorption-desorption characteristics of gas coal and coking coal," Chinese Journal of Rock Mechanics and Engineering, vol. 28, no. 8, pp. 1587-1592, 2009.

[20] E. Salehi, V. Taghikhani, C. Ghotbi, E. N. Lay, and A. Shojaei, "Theoretical and experimental study on the adsorption and desorption of methane by granular activated carbon at $25^{\circ} \mathrm{C}$," Journal of Natural Gas Chemistry, vol. 4, pp. 415-422, 2007.

[21] L. Xiangchun, N. Baisheng, Z. Ruming, and C. Leilei, "Experiment of gas diffusion and its diffusion mechanism in coal," International Journal of Mining Science and Technology, vol. 22, no. 6, pp. 885-889, 2012.

[22] R. M. Barrer, Diffusion in and through Solid, Cambridge University Press, Cambridge, UK, 1951.

[23] S. N. Zhou and J. Z. Sun, "Flow theory and application of coal seam gas," Journal of China Coal Society, vol. 2, pp. 24-36, 1965.

[24] E. M. Airey, "Gas emission from broken coal. An experimental and theoretical investigation," International Journal of Rock Mechanics and Mining Sciences, vol. 5, no. 6, pp. 475-494, 1968.

[25] Y. Y. Guo and S. N. Zhou, "Complete solution of flow law in one dimensional flow field of coal seam gas," Journal of China University of Mining and Technology, vol. 13, pp. 19-28, 1984.

[26] H. G. Yu, W. T. Fan, and M. Y. Sun, "Study on fitting models for methane isotherms adsorption of coals," Journal of China Coal Society, vol. 29, pp. 463-467, 2004.

[27] F. S. Karn, R. A. Friedel, and A. G. Sharkey, "Mechanism of gas flow through coal," Fuel, vol. 54, no. 4, pp. 279-282, 1975.

[28] H. Li, Y. Ogawa, and S. Simada, "Mechanism of methane flow through sheared coals and its role on methane recovery ${ }^{\text {और, }}$ Fuel, vol. 82, no. 10, pp. 1271-1279, 2003. 
[29] S. N. Zhou and B. Q. Lin, The Theory of Gas Flow and Storage in Coal Seams, China Coal Industry Publishing House, Beijing, China, 1999.

[30] Q. L. Yang, "Coal gas diffusion characteristics and its application," Satety In Coal Mines, vol. 5, pp. 1-6, 1987.

[31] Q. L. Yang and Y. A. Wang, "Mathematical simulation of the radial methane flow in spherical coal particles," Journal of China University of Mining and Technology, vol. 3, pp. 5561, 1988.

[32] D. M. Smith and F. L. Williams, "Diffusion models for gas production from coal: determination of diffusion parameters," Fuel, vol. 63, no. 2, pp. 256-261, 1984.

[33] D. M. Smith and F. L. Williams, "Diffusion models for gas production from coals: application to methane content determination," Fuel, vol. 63, no. 2, pp. 251-255, 1984.

[34] S. N. Zhou, "Mechanism of gas flow in coal seams," Journal of China Coal Society, vol. 15, pp. 61-67, 1990.

[35] S. Y. Wu and Y. Y. Guo, "Study on the characteristics of coalbed methane migration," Journal of China Coal Society, vol. 24, pp. 65-69, 1999.

[36] X. Q. He and B. S. Nie, "Diffusion mechanism of porous gases in coal seams," Journal of China University of Mining and Technology, vol. 30, pp. 1-4, 2001.

[37] B. S. Nie, Y. Y. Guo, and S. Y. Wu, "Mathematical model of gas diffusion in coal particle and analytical solution," Journal of China University of Mining and Technology, vol. 30, pp. 1922, 2001.

[38] E. Ruckenstein, A. S. Vaidyanathan, and G. R. Youngquist, "Sorption by solids with bidisperse pore structures," Chemical Engineering Science, vol. 26, no. 9, pp. 1305-1318, 1971.

[39] D. M. Smith and F. L. Williams, "Diffusional effects in the recovery of methane from coalbeds," Society of the Petroleum Engineers Journal, vol. 24, no. 5, pp. 529-535, 1984.

[40] Y. P. Qin, C. X. Wang, and J. Wang, "Mathematical model of gas emission in coal particles and the numerical solution," Journal of China Coal Society, vol. 37, no. 9, pp. 1466-1471, 2012.

[41] Y. W. Liu, J. P. Wei, Z. G. He, and M. J. Liu, "Influence rules and mechanisms of temperature on dynamic process of gas diffusion from coal particles," Journal of China Coal Society, vol. 38, no. 86, pp. 100-105, 2013.

[42] J. Luo, Y. Liu, C. Jiang, W. Chu, W. Jie, and H. Xie, "Experimental and modeling study of methane adsorption on activated carbon derived from anthracite," Journal of Chemical \& Engineering Data, vol. 56, no. 12, pp. 4919-4926, 2011.

[43] T. C. Ruppel, "Adsorption of methane on dry coal at elevated pressure," Fuel, vol. 53, no. 3, pp. 152-162, 1974.

[44] Z. Xiao-dong, S. Shu-xun, Q. Yong, Z. Jing, and T. Jia-xiang, "Isotherm adsorption of coal samples with different grain size," Journal of China University of Mining and Technology, vol. 34, no. 4, pp. 427-432, 2005.

[45] P. G. Sevenster, "Diffusion of gases through coal," Fuel, vol. 38, no. 4, pp. 403-418, 1959.

[46] Q. L. Yang and Y. A. Wang, "Diffusion theory and application of coal gas," Journal of China Coal Society, vol. 9, pp. 87-93, 1986.

[47] Y. W. Liu, Study on Gas Emission Rules, Mechanism and Dynamic Model from Coal Particle, Henan Polytechnic Uinversity, Jiaozuo, China, 2011. 